\title{
Gregarines modulate insect responses to sublethal insecticide residues
}

\author{
Marina Wolz ${ }^{1}$ - Alia Schrader ${ }^{1} \cdot$ Eileen Whitelaw $^{1} \cdot$ Caroline Müller $^{1}$ (I)
}

Received: 16 June 2021 / Accepted: 18 November 2021 / Published online: 1 December 2021

(c) The Author(s) 2021

\begin{abstract}
Throughout their lifetime, insects face multiple environmental challenges that influence their performance. Gregarines are prevalent endoparasites in most invertebrates that affect the fitness of their hosts, but are often overlooked in ecological studies. Next to such biotic factors, a current common challenge is anthropogenic pollution with pesticides, which causes a major threat to non-target organisms that are readily exposed to lethal or sublethal concentrations. In a laboratory study, we investigated whether the presence of gregarines modulates the food consumption and life history traits of a (non-target) leaf beetle species, Phaedon cochleariae, in response to sublethal insecticide exposure. We show that the larval food consumption of the herbivore was neither affected by gregarine infection nor sublethal insecticide exposure. Nevertheless, infection with gregarines led to a delayed development, while insecticide exposure resulted in a lower body mass of adult males and a reduced reproduction of females. Individuals exposed to both challenges suffered most, as they had the lowest survival probability. This indicates detrimental effects on the population dynamics of non-target insects infected with naturally occurring gregarines that face additional stress from agrochemical pollution. Moreover, we found that the infection load with gregarines was higher in individuals exposed to sublethal insecticide concentrations compared to unexposed individuals. To counteract the global decline of insects, the potential of natural parasite infections in modulating insect responses to anthropogenic and non-anthropogenic environmental factors should be considered in ecological risk assessment.
\end{abstract}

Keywords Combined challenges $\cdot$ Fitness $\cdot$ Gregarines $\cdot$ Leaf beetle $\cdot$ Pyrethroid

\section{Introduction}

Throughout their lifetime, organisms have to cope with a large number of environmental challenges including parasite infections. In invertebrates, gregarines (Apicomplexa) are probably one of the most common endosymbionts, often considered as endoparasites (Locklin and Vodopich 2010; Logan et al. 2012). They can lead to a delayed development, higher mortality, and reduced reproduction of their hosts (Zuk 1987a; Córdoba-Aguilar et al. 2003). Nutrient deprivation induced by the gregarines may be causing some of these negative effects (Gigliolli et al. 2016). However, gregarine infections can also be benign for their hosts (Harry

Communicated by Sascha Rösner.

Caroline Müller

caroline.mueller@uni-bielefeld.de

1 Department of Chemical Ecology, Bielefeld University, Universitätsstr. 24, 33615 Bielefeld, Germany
1967; Kim et al. 2014) or even beneficial, for example, by accelerating the development or lowering predation (Alarcón et al. 2017; Soghigian et al. 2017). The relationship between gregarines and their hosts, i.e., whether parasitic, neutral, or mutualistic, seems to be highly species-specific and depending on the gregarine load (Zuk 1987a; Field and Michiels 2005; Rueckert et al. 2019). Furthermore, the fitness of the host may alter the outcome of the interaction, for example, under suboptimal environmental conditions. Little is known about such interactive effects between gregarines and other environmental factors that affect insect life histories.

One of these factors is anthropogenic stress such as agrochemical pollutants that have a huge impact on organisms and ecosystems (Köhler and Triebskorn 2013; Guedes et al. 2016; Müller 2018). For example, insecticide residues are known to impact the behaviour, physiological processes and fitness-related parameters of various invertebrates that are not targeted on purpose by the pesticides (Stark and Banks 2003; Desneux et al. 2007). The specific effects depend on the mode of action of the insecticide, the 
concentration the organism is facing, and the invertebrate species itself (Guedes et al. 2017; Müller 2018). Pyrethroids are a widely used class of insecticides, which act as neurotoxins by retarding the closing of sodium channels (Soderlund et al. 2002). In that way, sublethal concentrations of pyrethroids pose a threat to target pests but also to non-target arthropods, which respond with locomotor deficits, a lower survival, and/or reduced reproduction (Desneux et al. 2004; Ceuppens et al. 2015; Charreton et al. 2015). Such negative consequences of exposure to agrochemical pollutants may become even worse if insects are already challenged by other environmental factors such as parasites.

Studies which considered the effects of parasites and pesticides on (non-target) organisms indicate increased detrimental effects on fitness-related traits when these challenges were tested in combination (Coors and De Meester 2008; Fauser-Misslin et al. 2014; Botías et al. 2021). For example, bumblebee colonies (Bombus terrestris) infected with a microsporidium gut parasite and exposed to different insecticides showed reduced growth (Fauser-Misslin et al. 2014). Survival of water flea populations (Daphnia magna) was reduced by synergistic negative actions of parasitism and exposure to the insecticide 1-naphthyl methylcarbamate (Coors and De Meester 2008). To our knowledge, studies investigating the consequences of a gregarine infection on terrestrial arthropods in combination with insecticide exposure are lacking. However, detrimental effects on fitness can occur as responses of gregarine-infected hosts exposed to suboptimal food conditions (Harry 1967; Zuk 1987b). These effects may be similar to responses of gregarine-infected hosts to sublethal insecticide exposure, because such exposure leads to a suppressed food intake, as shown, for example, in adults of the mustard leaf beetle Phaedon cochleariae (Coleoptera: Chrysomelidae) (Wolz et al. 2021).

Larvae and adults of $P$. cochleariae feed on different Brassicaceae plants and can be infected with a prevalent gregarine species that colonises the gut (Müller et al. 2017a). The gregarine load of the larvae has been shown to relate to the host plant species and thus food quality (Müller et al. 2017a). The habitat of the leaf beetle includes both agricultural and natural areas. In the latter, it can be considered as a non-target organism (Müller and Müller 2016) that faces traces of insecticides either through misapplication or drift from insecticide spray dust. Exposure of adults to sublethal concentrations of the pyrethroid $\lambda$-cyhalothrin resulted in impaired food consumption, delayed development, and reduced reproduction in the exposed as well as the subsequent unexposed generation (Müller et al. 2017b, 2019a; Wolz et al. 2021). In larvae, sublethal $\lambda$-cyhalothrin exposure caused detrimental effects on different life history traits and altered interspecific interactions with potential predators (Müller et al. 2019b).
To understand whether the presence/absence of a biotic challenge can modulate insect responses to an anthropogenic environmental stressor, we investigated the effects of gregarine infection and larval exposure to a sublethal concentration of $\lambda$-cyhalothrin. Therefore, we studied the effects of both factors individually and in combination on the food consumption and several life history traits, using $P$. cochleariae as a suitable model. Moreover, we assessed the infection load with gregarines in larvae and adult beetles. Based on the assumption that gut endoparasites deprive nutrients from the host, we expected an increased food consumption by gregarine-infected larvae. We predicted that consumption is also enhanced after insecticide exposure, as a suppressed food intake during insecticide exposure may be compensated. Furthermore, we hypothesised that an infection of $P$. cochleariae with gregarines is not harmful, but in combination with a sublethal insecticide exposure, life history traits are impaired, leading to a reduced fitness. Finally, we expected that detrimental insecticide exposure leads to a higher number of gregarines in the host.

\section{Materials and methods}

\section{Study organism and rearing}

A rearing of $P$. cochleariae was maintained for several generations at Bielefeld University under constant climatic conditions $\left(20{ }^{\circ} \mathrm{C}, 16 \mathrm{~h}: 8 \mathrm{~h}\right.$ light: dark, $70 \%$ r.h.). Adult beetles were mixed randomly for mating and groups of 100-200 individuals kept in boxes $(20 \times 20 \times 6.5 \mathrm{~cm})$ covered with gauze lids. Every year, the rearing population was replenished with individuals collected in the field $\left(51^{\circ} 51^{\prime} 21^{\prime \prime} \mathrm{N}\right.$, $8^{\circ} 41^{\prime} 37^{\prime \prime}$ E). Larvae and beetles were supplied with leaves of non-flowering 8-10-week-old cabbage plants (Brassica rapa L. spp. pekinensis), which were cultivated in pots in a greenhouse $\left(20{ }^{\circ} \mathrm{C}, 16 \mathrm{~h}\right.$ : $8 \mathrm{~h}$ light: dark, $70 \%$ r.h.). For the experiment, only middle-aged leaves were offered, and larvae were provided with greenhouse-grown cabbage, while adults received cabbage bought from an organic store due to plant shortage.

\section{General experimental set-up and measurements of larval food consumption and life history traits}

A full-factorial design was set up to test the influences of gregarine infection and sublethal insecticide exposure on larval consumption and life history of $P$. cochleariae. Threeweek-old adults (about 200 individuals) were provided with cabbage leaves and their offspring was subsequently used for the experiment. Female beetles bite little cavities in the leaf surface, lay individual eggs in these cavities, and cover the eggs with secretion (Müller and Rosenberger 2006). 
Infection of larvae of $P$. cochleariae with gregarines occurs via the uptake of spores excreted by infected conspecifics (Müller, unpublished). Faecal remains can also cover the eggs. Thus, after $24 \mathrm{~h}$ of oviposition time, eggs were carefully removed from the leaves and the secretion and potential faeces removed with a paintbrush and tap water. Eggs were placed on fresh cabbage leaves and randomly distributed over two rearing boxes, one assigned to the uninfected gregarine treatment $(\mathrm{G}-: N=325)$ and the other to the gregarine-infection treatment $(\mathrm{G}+: N=320)$. Hatching larvae (G-: $N=195, \mathrm{G}+: N=204)$ were supplied with the respective food sources for 4 days as described below (experimental infection of $P$. cochleariae larvae with gregarines) to ensure a $\mathrm{G}$ - or $\mathrm{G}+$ treatment.

At the fourth day after hatching, the larvae were divided into groups of 5-10 larvae in large Petri dishes $(9 \mathrm{~cm}$ diameter) lined with filter paper and provided with cabbage leaf pieces $(3 \times 4 \mathrm{~cm})$. From day 5 on, half of both $\mathrm{G}-$ and $\mathrm{G}+$ larvae were assigned to one of the two insecticide treatment groups, either receiving no insecticide $(\mathrm{I}-)$ or receiving $\lambda$-cyhalothrin-treated leaf discs $(\mathrm{I}+)$ for $48 \mathrm{~h}$ (procedure see below), resulting in four treatment groups $(\mathrm{G}-\mathrm{I}-$ : $N=50, \mathrm{G}-\mathrm{I}+: N=113, \mathrm{G}+\mathrm{I}-: N=60, \mathrm{G}+\mathrm{I}+: N=130)$. Much higher numbers of $\mathrm{I}+$ animals were set up to account for a lower survival of insecticide-exposed individuals. From day 7 after hatching, all individuals were provided with untreated cabbage leaves (ESM Fig. S1).

To investigate the effects of the different treatments on consumption, the amount of leaf mass consumed within $24 \mathrm{~h}$ by each larva was measured. At day 9 after hatching, two larvae were randomly selected from each Petri dish. Each larva was weighed (microbalance, ME36S, Sartorius AG, Göttingen, Germany), placed in a small Petri dish $(5.5 \mathrm{~cm}$ diameter) lined with moistened filter paper and offered a leaf disc (24 mm diameter) of known mass (balance, LA120SOCE, Sartorius AG, Göttingen, Germany). After $24 \mathrm{~h}$, the larvae were weighed again and the remaining leaf discs were scanned (Samsung ProXpress SL-M3375FD, Schwalbach/ Taunus, Germany; resolution: $600 \mathrm{dpi}$ ). The remaining leaf area was determined with ImageJ (v 1.52a) and used to calculate the consumed leaf mass [initial leaf mass $\times$ (initial leaf disc area - remaining leaf area)/initial leaf disc area]. Afterwards, these larvae remained in their individual Petri dishes and were used for counting of gregarines (see below).

To test the effects of the different treatments on life history traits, pupae were individually placed in small Petri dishes lined with filter paper and the time from larval hatching until adult eclosion was noted. The body mass of adult individuals was measured $24 \mathrm{~h}$ after adult eclosion and the sex of the individuals determined. Adults were kept individually in small Petri dishes and supplied with cabbage leaves. Eight days after adult eclosion females were mated with males of the same treatment group, placing each male to one female for $24 \mathrm{~h}$. After mating, the pairs were separated again, and the number of eggs laid within the subsequent 4 days per female was counted. The hatching rate was determined by counting the number of hatched larvae relative to the number of eggs laid. Moreover, the survival of all individuals kept under the four treatment regimes was noted until day 10 after adult eclosion. The experiment was ended when adults were 15 days old, while adults can live up to 3 months (Bogdanov-Katjkov 1923).

\section{Experimental infection of $P$. cochleariae larvae with gregarines}

To ensure larval infection with gregarines $(G+$ treatment $)$, leaves covered with faeces were taken that had been placed in the boxes of the insect rearing stock for $24 \mathrm{~h}$. Random examinations of the rearing stock showed that all tested beetles were infected with gregarines and that infectious spores were present in their faeces. Larvae of the $\mathrm{G}$ - treatment were offered leaves that had been kept for $24 \mathrm{~h}$ in a box without conspecifics and were damaged by regular cuttings to imitate feeding and thus provide leaves of comparable quality to those provided to the $\mathrm{G}+$ group. Such leaves were offered to hatching larvae of the respective treatment groups and replaced every 2 days until larvae were 4 days old. Microscopy of larvae and adults (see below) confirmed that all dissected individuals of the $\mathrm{G}$ - treatment $(N=40$ larvae, $N=46$ adults) were not infected, while all individuals of the $\mathrm{G}+$ treatment were successfully infected with gregarines $(N=40$ larvae, $N=73$ adults $)$.

\section{Preparation of sublethal $\lambda$-cyhalothrin concentration and insecticide exposure treatment}

The pyrethroid $\lambda$-cyhalothrin was chosen as contact insecticide, because it is widely used in agriculture, including fields with crops of Brassicaceae (Soderlund et al. 2002). A sublethal concentration was prepared from the insecticide LAMBDA WG, which contains $5 \%$ of the active toxin $\lambda$-cyhalothrin (Syngenta 2016). The insecticide was dissolved in methanol (HPLC-grade, VWR International $\mathrm{GmbH}$, Darmstadt, Germany) and centrifuged, and the supernatant used to prepare a $0.6 \mathrm{mg} / \mathrm{L} \lambda$-cyhalothrin stock solution. This concentration was considered as sublethal, as less than $50 \%$ of the larvae died during the exposure period (following the definition by de França et al. (2017)). In an agricultural system, this concentration is approximately less than half of the application recommended by the supplier (Syngenta 2016) and may thus occur in areas close to treated fields as residue. The experimental larvae were fed on days 5 and 6 after hatching with cabbage leaf discs (24 mm diameter) treated with $76.8 \mu \mathrm{L}$ methanol $(\mathrm{I}-)$ or $\lambda$-cyhalothrin solution $(\mathrm{I}+)$. The surfaces of the leaf discs were evenly 
covered with the respective solutions using a pipette and leaf discs were kept under a fume hood until evaporation of the solvent (at least $20 \mathrm{~min}$ ) before offering them to the larvae. Depending on the number of larvae, two-to-four leaf discs were offered per Petri dish to provide food ad libitum, and after one day, the leaf discs were exchanged by discs of the respective treatments for another day.

\section{Counting of gregarines}

Subgroups of both larvae and adults of $P$. cochleariae were examined to test whether the number of gregarines depends on the different treatments and developmental stage of the host. At day 12 after larval hatching, a subset of larvae of the different treatments (two larvae per Petri dish, used for consumption assay, $N=20$ larvae per treatment group) was taken and individuals were frozen $\left(-20{ }^{\circ} \mathrm{C}\right)$. Likewise, adult males and females of each treatment group $(\mathrm{G}-\mathrm{I}-: N=9$ females, $N=12$ males; $\mathrm{G}-\mathrm{I}+: N=12$ females, $N=13$ males; $\mathrm{G}+\mathrm{I}-: N=12$ females, $N=15$ males; $\mathrm{G}+\mathrm{I}+$ : $N=26$ females, $N=20$ males) were randomly selected and frozen at day 15 after adult eclosion. Afterwards, individuals were thawed, the midgut dissected, spread on a microscope slide in $25 \mu \mathrm{L}$ sodium phosphate buffer $(0.1 \mathrm{M}, \mathrm{pH}=7.2)$, and the number of gregarines (likely as trophozoites and gamonts) counted under a light microscope at 200-400 times magnification (ZEISS Axiophot, Carl Zeiss Microscopy $\mathrm{GmbH}$, Jena, Germany) (ESM Fig. S2).

\section{Statistical analyses}

All statistical analyses were performed in $\mathrm{R}$ version 3.6.3 ( $\mathrm{R}$ Core Team 2020) with RStudio version 1.2.5033 (RStudio Team 2019). Data were analysed using linear models ( $(\mathrm{m})$, generalised linear models (glm) (package MASS; Venables and Ripley 2002), and cox proportional hazard models (package survival; Therneau 2020). Model assumptions for $\mathrm{lms}$ and glms (normal distribution and homoscedasticity of residuals) and cox proportional hazard models (proportional hazard and influential observations) were checked using diagnostic plots. Stepwise backward model selection was applied to obtain the minimal adequate models. Based on $\mathrm{F}$ test or Chi-square test results (package MASS; Venables and Ripley 2002), non-significant $(P$-value $>0.05)$ interaction terms and/or predictors were excluded from the models.

The effects of the predictors gregarine treatment and insecticide treatment as well as their interaction on development time (from larval hatching to adult eclosion) were tested using a glm (Poisson distribution, identity link function). The influences of the predictors larval body mass, gregarine treatment, and insecticide treatment and their interaction on the food consumption of larvae were analysed using a $1 \mathrm{~m}$. The effects of the predictors gregarine treatment, insecticide treatment, as well as their interaction on the adult body mass were analysed separately for males and females using $1 \mathrm{~m}$. Glms were performed to investigate the effects of gregarine treatment, insecticide treatment and their interaction on the number of eggs laid by adult females (Poisson distribution, log link function), and the hatching rate of larvae [binomial family (success/failure of hatching), logit link function]. To investigate the effects of insecticide treatment on the gregarine load in the larval stage, a glm (Poisson distribution, identity link function) was calculated. For the gregarine load in adults, a glm (Poisson distribution, identity link function) with insecticide treatment and sex as predictors was performed. The influences of the predictors gregarine treatment, insecticide treatment, and their interaction on survival probability were tested using a cox model, followed by pairwise log-rank post hoc tests. Survival data were plotted using Kaplan-Meier curves (package survival; Therneau 2020).

\section{Results}

\section{Effects of gregarine infection and sublethal $\lambda$-cyhalothrin exposure on larval food consumption and life history traits}

The food consumption of larvae was neither influenced by gregarine treatment nor insecticide treatment, but was significantly affected by the larval body mass $(\operatorname{lm}: d f=1, F=20.2$, $P<0.001 ; \mathrm{G}-\mathrm{I}-: N=24, \mathrm{G}-\mathrm{I}+: N=26, \mathrm{G}+\mathrm{I}-: N=20$, $\mathrm{G}+\mathrm{I}+: N=24)$. Heavier larvae consumed less leaf material than lighter larvae (Fig. 1A).

The developmental time was significantly affected by the gregarine treatment (Table 1). Uninfected larvae developed on average about $1.5(\mathrm{I}+)$ to $2(\mathrm{I}-)$ days faster compared to the gregarine-infected insects (Fig. 1B).

Neither the body mass of females nor that of males was affected by the gregarine treatment (Table 1, Fig. 1C, D). However, the body mass of the males was significantly influenced by insecticide exposure, with $\mathrm{I}+$ beetles being lighter than I - individuals.

Female reproduction was not affected by gregarine treatment, but insecticide treatment had a significant impact on the number of eggs laid and the hatching rate (Table 1). When not exposed to insecticides, females laid on average between $4 \%(\mathrm{G}-)$ and $14 \%(\mathrm{G}+)$ more eggs compared to insecticide-exposed females (Fig. 2A). In contrast, the hatching success of unexposed females was on average $18 \%$ lower in the uninfected group $(\mathrm{G}-)$ and $3 \%$ in the gregarineinfected group $(\mathrm{G}+)$ compared to the insecticide-exposed females (Fig. 2B).

The survival probability of $P$. cochleariae ranged between 50 and $90 \%$ at 10 days after adult eclosion (Fig. 2C). The 
Fig. 1 Effects of gregarine (G) treatment and insecticide (I) treatment on larval food consumption (fresh weight) (A), development time (B), and adult body mass of females $(\mathbf{C})$ and males (D) of Phaedon cochleariae. Overlaid lines for the food consumption represent model predictions of linear model with associated SE as polygons around the lines and raw data points (open circles: $\mathrm{G}-\mathrm{I}-$, filled circles: $\mathrm{G}-\mathrm{I}+$, open triangles: $\mathrm{G}+\mathrm{I}-$, and filled triangles: $\mathrm{G}+\mathrm{I}+$ ). Box plots are overlaid with raw data and show the medians (horizontal lines), means (crosses), 25th and 75th percentiles, and $1.5 \times$ lower and upper quartiles (whiskers)
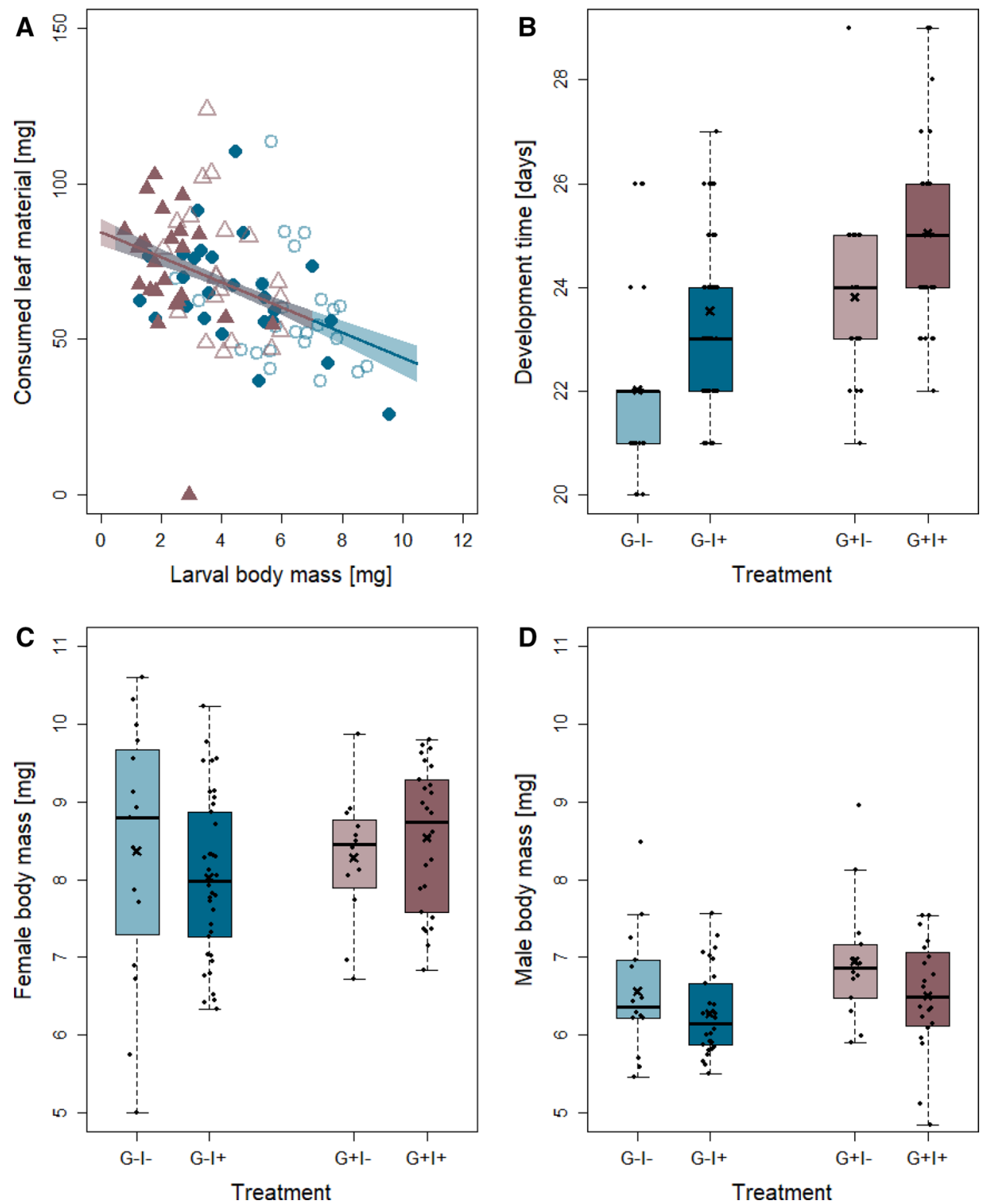

survival probability was influenced by the interaction of gregarine treatment and insecticide treatment (cox model: $X^{2}=4.4, P=0.036, \mathrm{G}+\mathrm{I}-: N=35, \mathrm{G}-\mathrm{I}+: N=101$, $\mathrm{G}+\mathrm{I}-: N=28, \mathrm{G}+\mathrm{I}+: N=89)$. Individuals with gregarine infection and no insecticide exposure $(\mathrm{G}+\mathrm{I}-)$ had the highest survival, whereas gregarine infection and insecticide exposure $(\mathrm{G}+\mathrm{I}+)$ resulted in the lowest survival probability.

\section{Effects of sublethal $\lambda$-cyhalothrin exposure on gregarine load}

No gregarines were found in the $\mathrm{G}-$ individuals $(N=40$ larvae, $N=46$ adults). In the gregarine-infected animals, significantly less gregarines were found in unexposed than in insecticide-exposed larvae (glm: $d f=1, X^{2}=157.8, P<0.001$,
$\mathrm{G}+\mathrm{I}-: N=20, \mathrm{G}+\mathrm{I}+: N=20$ ) (Fig. 3A). In adults, the number of gregarines was likewise significantly affected by the insecticide treatment (glm: $d f=1, X^{2}=417.31, P<0.001$, $\mathrm{G}-\mathrm{I}+: N=12$ females, $N=15$ males; $\mathrm{G}+\mathrm{I}+: N=26$ females, $N=20$ males) and in addition by the sex of the beetles (glm: $d f=1, X^{2}=66.72, P<0.001$ ). As in the larvae, unexposed adult beetles showed less gregarines, but overall females were more heavily infected by gregarines than males (Fig. 3B).

\section{Discussion}

Our study revealed that the two challenges, infection with gregarines and larval exposure to sublethal $\lambda$-cyhalothrin concentrations, had distinct effects on $P$. cochleariae when 
Table 1 Effects of gregarine treatment and insecticide treatment on performance traits of Phaedon cochleariae

\begin{tabular}{|c|c|c|c|}
\hline Trait & $d f$ & $F / X^{2}$ & $P$ \\
\hline \multicolumn{4}{|l|}{ Development } \\
\hline Gregarine treatment $(\mathrm{G})$ & 1 & 3.9 & 0.046 \\
\hline \multicolumn{4}{|l|}{ Female body mass } \\
\hline Gregarine treatment $(\mathrm{G})$ & 1 & 1.9 & 0.172 \\
\hline \multicolumn{4}{|l|}{ Male body mass } \\
\hline Insecticide treatment (I) & 1 & 5.5 & 0.021 \\
\hline \multicolumn{4}{|l|}{ Number of eggs } \\
\hline Insecticide treatment (I) & 1 & 8.9 & $<0.01$ \\
\hline \multicolumn{4}{|l|}{ Hatching rate } \\
\hline Insecticide treatment (I) & 1 & 36.5 & $<0.001$ \\
\hline
\end{tabular}

Results are based on the minimal adequate model (only predictors are shown that remained in each model). For linear models, (lm) $F$-values and for generalised linear models $(\mathrm{glm})$ Wald $X^{2}$-values are shown. Significant $P$ values $(P<0.05)$ are indicated in bold. Number of replicates per treatment group between 12 and 47

tested individually or in combination. Against our expectation, larval food consumption was neither significantly affected by gregarine infection nor by sublethal insecticide exposure, but highly dependent of the larval body mass. It has been suggested that an infection of the gut with gregarines leads to a depletion of nutrients (Gigliolli et al. 2016), and therefore, we assumed an enhanced food consumption to compensate for such depletion. However, in other insects, such as the European earwig (Forficula auricularia), gregarine infection did not alter the food intake of the host (Arcila and Meunier 2020). In contrast, a gregarine infection for 20 days significantly reduced food intake in the tobacco grasshopper (Atractomorpha crenulata), which consequently had a lower body mass (Johny et al. 2000). Thus, effects on consumption may be species-specific and/or depend on the timing of events. In our experiment with $P$. cochleariae, the time span between the gregarine infection and the food consumption assay was relatively short (5 days in between). At a later time point, when gregarines developed further in the larval midgut, insect larvae may become more deprived of nutrients.

Larvae of $P$. cochleariae can regulate their food consumption depending on the quality of their food (Tremmel and Müller 2013) and adults increased their food consumption several days after a 2 -week exposure to a sublethal $\lambda$-cyhalothrin concentration (Wolz et al. 2021), presumably to compensate for the reduced food intake during exposure. In the present study, we exposed the larvae for a relatively short time (2 days), which probably caused a less drastic reduction in food intake, and thus, no compensatory food consumption was observed. Nevertheless, food consumption of these larvae was highly dependent on their body mass, with lighter larvae consuming more than heavier larvae. Interestingly, larvae of $P$. cochleariae with gregarine infection were lighter than larvae without gregarine infection (see ESM S3). A higher consumption of lighter individuals may be necessary to catch up and reach a similar larval body mass as uninfected individuals before entering metamorphosis.
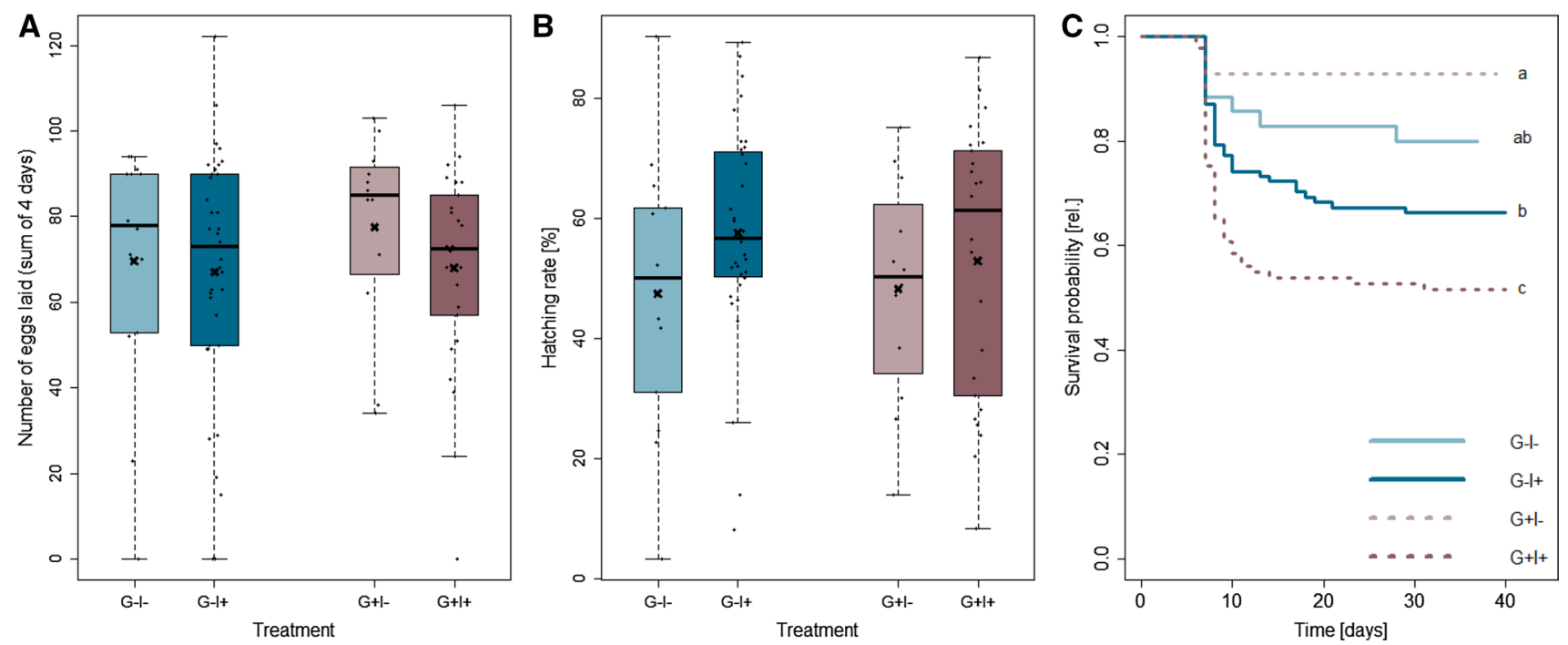

Fig. 2 Effects of gregarine $(\mathrm{G})$ treatment and insecticide (I) treatment on number of eggs laid (A), hatching success (B) and survival probability (C) of Phaedon cochleariae. Box plots are overlaid with raw data, and show the medians (horizontal lines), means (crosses), 25th and 75 th percentiles, and $1.5 \times$ lower and upper quartiles (whiskers).
The survival rates are illustrated as Kaplan-Meier survival curves. The survival was scored from larval hatching until day 10 after adult eclosion (initial G $-\mathrm{I}-: N=35, \mathrm{G}-\mathrm{I}+: N=101, \mathrm{G}+\mathrm{I}-: N=28$, $\mathrm{G}+\mathrm{I}+: N=89)$ per treatment group. Different lower case letters indicate significant differences between treatment groups 
Fig. 3 Effects of insecticide (I) treatment on number of gregarines (likely trophozoites and gamonts) in larvae (A) and adult females and males $(\mathbf{B})$ of Phaedon cochleariae. Box plots are overlaid with raw data, and show the medians (horizontal lines), means (crosses), 25th and 75 th percentiles, and $1.5 \times$ lower and upper quartiles (whiskers). No gregarines were found in $\mathrm{G}$ - animals
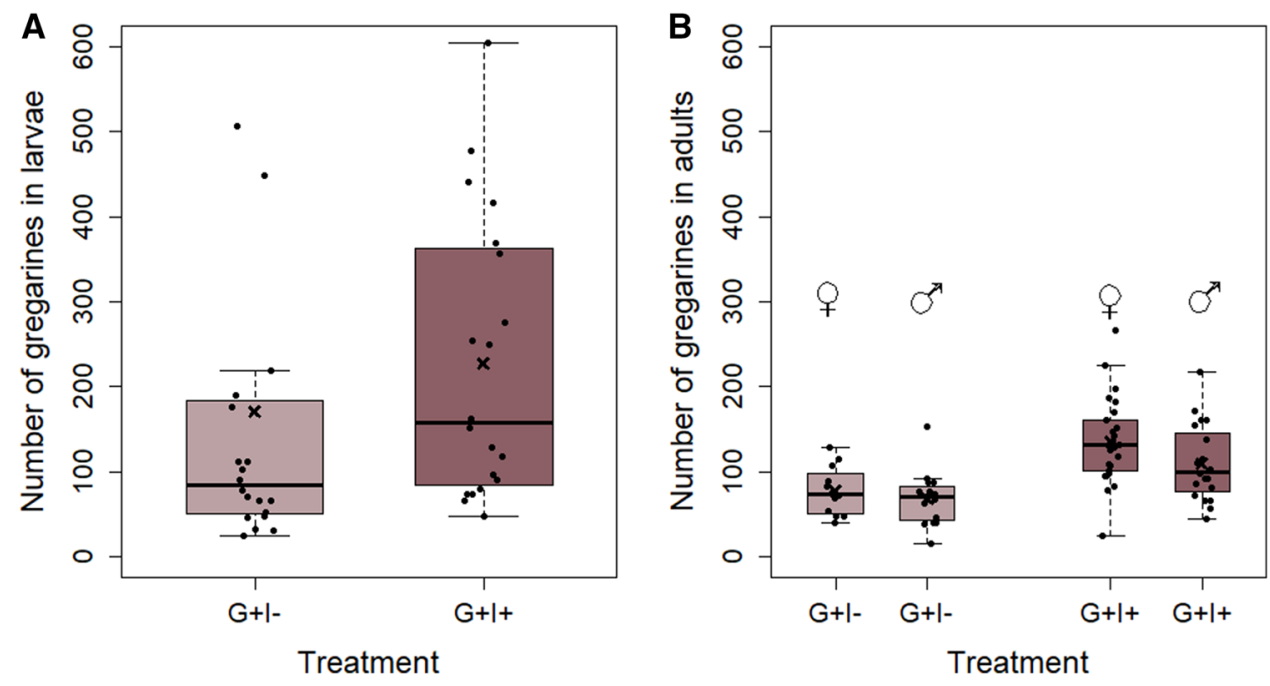

An infection with gregarines resulted in a delayed development, which is likewise known for other terrestrial arthropods (Zuk 1987a; Thomas and Rudolf 2010; Gigliolli et al. 2016). This negative effect of gregarines on larval development was independent of insecticide exposure, in contrast to our initial hypothesis that gregarine infection only in combination with another challenge, i.e., sublethal insecticide exposure, leads to a reduced fitness. An extended development time of the larvae, which are usually less mobile than the adults, may enhance their predation risk (Häggström and Larsson 1995) and reduce the number of generations per year (Cole 1954). A slower development is often associated with a restriction in resources during early life development (Metcalfe and Monaghan 2001). In addition to nutrient deprivation, an accumulation of gregarines can hinder the passage of food or lead to morphological (e.g., damage of epithelial cells in midgut) and physiological alterations (e.g., impaired hormone regulation), interfering with the host development (Sanders and Poinar 1973; Gigliolli et al. 2015). Overall, gregarines may cause metabolic costs, which ultimately lead to a delayed development, which was also reflected in the reduced larval body mass of $P$. cochleariae larvae at day 9 (see ESM S3).

Other life history traits than larval development were not affected by the gregarine infection in the present study, but in part by the insecticide exposure. Only males, but not females, showed a reduced body mass, but females produced less eggs when exposed as larvae to $\lambda$-cyhalothrin. In general, responses to environmental stress in larval stages can affect allocation patterns to later life history traits like adult body mass, size, or reproduction (Boggs 2009; Dmitriew and Rowe 2011). The negative consequences of the larval insecticide exposure on male body mass and egg deposition may result from resource- and energy-demanding metabolic detoxification processes (Dawkar et al. 2013; Hafeez et al. 2020). A low male body mass can negatively affect reproduction, as it may influence mating success (Candolin 2005; Murphy and Krupke 2011). For females, exposure to pyrethroids in larval stages is known to lead to a reduced fat content in adult damselflies (Coenagrion scitulum) (Dinh et al. 2016), which may result in less energy allocation towards egg production. Whether the fat content of females of $P$. cochleariae is affected by insecticide exposure of the larvae remains to be tested.

Despite the reduction in the number of eggs laid, the hatching rate of larvae from these eggs was higher in individuals that had experienced larval insecticide exposure. Laying fewer eggs but providing them with more resources may reflect a trade-off to compensate for limited resources, which has been found, for example, in soil mites (Sancassania berlesei) and European earwigs (Benton et al. 2005; Koch and Meunier 2014). Alternatively, the higher hatching rate may point to a hormetic effect, i.e., stimulatory effects of low levels of insecticide on reproduction (Guedes et al. 2010). Hormetic effects have been, for example, found in adults of the Colorado potato beetle (Leptinotarsa decemlineata), which had a higher body mass and were more likely to survive if the larvae had been exposed to a pyrethroid (Margus et al. 2019). However, it is questionable how persistent this positive effect on the hatching success of $P$. cochleariae is, as we did not measure the reproductive output of the females across lifetime, but only over a limited time period. Finally, not all eggs may have been fertilized, which may have contributed to reduced hatching rates.

In line with our expectation, the combination of gregarine infection and insecticide exposure resulted in the lowest survival probability of $P$. cochleariae, indicating that potential detrimental effects of a gregarine infection sometimes only become apparent when insects are exposed to additional environmental challenges. In contrast, gregarine-infected individuals without insecticide exposure showed the highest survival probability, which points in the direction of a 
mutualistic relationship between host and gregarine. Therefore, the classification of gregarines as parasites is not fully justified for the leaf beetle and shows that gregarines should be more neutrally considered as endosymbionts (Rueckert et al. 2019). The switch of a symbiotic relationship between host and "parasite" from mutualistic to parasitic can be triggered by extreme environmental conditions, such as starvation (Harry 1967; Zuk 1987a; Moran et al. 2020). The outcome of such interactions is moreover highly speciesspecific. For example, starvation in combination with a high gregarine infection led to a higher survival probability in the European earwig (Arcila and Meunier 2020), but a lower longevity of field crickets (Zuk 1987b). Because the counting of gregarines is invasive, we could not compare the gregarine load for dead individuals with individuals still living. However, our data may indicate a negative relationship at the larval stage, where mortality is peaking.

Furthermore, our results revealed that insecticide exposure increased the number of gregarines found in both larvae and adults of $P$. cochleariae. This finding may be attributed to weakening of the host by the insecticide, for example, through resource-demanding detoxification processes that can lower the immune protection (Rivero et al. 2010). A higher gut parasite load by Nosema spp. has been detected in honeybees exposed to imidacloprid (Pettis et al. 2012), and likewise, more tapeworms (Hymenolepis diminuta) were found in mealworm beetles (Tenebrio molitor) following pyrethroid exposure (Dhakal et al. 2020) compared to insects without insecticide exposure. Other studies suggest that the gregarine-infection level plays a crucial role in the effect of gregarines on their hosts, with higher loads causing obviously negative effects (Sulaiman 1992; Field and Michiels 2005).

In adults of $P$. cochleariae, the number of gregarines was lower than in the larvae. It is unknown how and in which stage gregarines persist across the metamorphosis in this beetle species. In the red flour beetle (Tribolium castaneum), the gregarines are likely excreted during metamorphosis (Thomas and Rudolf 2010; Critchlow et al. 2019). A reinfection of adults of this species resulted in a significantly reduced gregarine load, if larvae had been already infected (Thomas and Rudolf 2010), providing evidence for an immune-priming process in gregarineinfected individuals. Furthermore, we detected a higher gregarine-infection load of females compared to males of $P$. cochleariae. Sex-specific differences in the gregarine prevalence have been reported for earwigs and odonate species, with biases towards males (Córdoba-Aguilar and Munguía-Steyer 2013; Arcila and Meunier 2020) or females (Bunker et al. 2013), but also no sex-differences have been found (Ilvonen et al. 2016). The differences in prevalence may be attributed to differences in behaviour between the sexes. For instance, sex-specific food intake may lead to an uptake of more spores in the sex that consumes more food (Hecker et al. 2002). Alternatively, a higher infection load in females compared to males of the leaf beetle may be due to their size dimorphism; females are heavier compared to males and may therefore host a higher number of gregarines by potentially providing more resources. Irrespective of the causes, we likely can exclude an additional burden by gregarines on females, as their reproduction was not impaired by gregarines.

In conclusion, our study revealed that both naturally prevalent gregarines and sublethal pyrethroid exposure, at least in the concentration tested here, impact different fitness traits of a leaf beetle species individually or in combination. The interactive negative effects of both factors on survival indicate a very complex relationship between challengers and the host. Under field conditions, combined effects may be enhanced in stressful natural environments, in which individuals likely face numerous challenges. Similar effects may be expected for other (non-target) insects, although the influence of gregarines is mostly host-specific. Therefore, to counteract the global decline of insects, the potential of natural parasite infections in modulating insect responses to anthropogenic and non-anthropogenic environmental factors should be considered for ecological risk assessment and their effects on ecosystems.

Supplementary Information The online version contains supplementary material available at https://doi.org/10.1007/s00442-021-05086-4.

Acknowledgements We thank the gardeners of Bielefeld University for plant cultivation, the working group of Christian Kaltschmidt for providing access to the ZEISS Axiophot microscope, and Sonja Rueckert for valuable comments on the manuscript.

Author contribution statement MW and CM conceived the project and designed the experiment; MW, AS, and EW performed the bioassays, EW counted the gregarines. MW analysed the data statistically and wrote the manuscript with feedback from CM. All authors gave the final approval for publication.

Funding Open Access funding enabled and organized by Projekt DEAL.

Data availability All data and code from this study are available via the Dryad Digital Repository (https://doi.org/10.5061/dryad.k6djh9w6h).

\section{Declarations}

Conflict of interests The authors declare that they do not have any competing interests.

Consent for publication All authors have given their consent for the publication of this manuscript.

Consent to participate All authors have given their consent to participate in this manuscript.

Ethics statement Not applicable. 
Open Access This article is licensed under a Creative Commons Attribution 4.0 International License, which permits use, sharing, adaptation, distribution and reproduction in any medium or format, as long as you give appropriate credit to the original author(s) and the source, provide a link to the Creative Commons licence, and indicate if changes were made. The images or other third party material in this article are included in the article's Creative Commons licence, unless indicated otherwise in a credit line to the material. If material is not included in the article's Creative Commons licence and your intended use is not permitted by statutory regulation or exceeds the permitted use, you will need to obtain permission directly from the copyright holder. To view a copy of this licence, visit http://creativecommons.org/licenses/by/4.0/.

\section{References}

Alarcón ME, Jara A, Briones RC, Dubey AK, Slamovits CH (2017) Gregarine infection accelerates larval development of the cat flea Ctenocephalides felis (Bouché). Parasitology 144:419-425. https://doi.org/10.1017/s0031182016002122

Arcila F, Meunier J (2020) Friend or foe? The apparent benefits of gregarine (Apicomplexa: Sporozoa) infection in the European earwig. Int J Parasitol 50:461-469. https://doi.org/10.1016/j.ijpara. 2020.01.007

Benton TG, Plaistow SJ, Beckerman AP, Lapsley CT, Littlejohns S (2005) Changes in maternal investment in eggs can affect population dynamics. Proc R Soc B Biol Sci 272:1351-1356. https://doi. org/10.1098/rspb.2005.3081

Bogdanov-Katjkov NN (1923) Der Meerrettichblattkäfer Phaedon cochleariae F. Suppl Entomol 9:23-26

Boggs CL (2009) Understanding insect life histories and senescence through a resource allocation lens. Funct Ecol 23:27-37. https:// doi.org/10.1111/j.1365-2435.2009.01527.x

Botías C, Jones JC, Pamminger T, Bartomeus I, Hughes WOH, Goulson D (2021) Multiple stressors interact to impair the performance of bumblebee Bombus terrestris colonies. J Anim Ecol 90:415431. https://doi.org/10.1111/1365-2656.13375

Bunker BE, Janovy J, Tracey E, Barnes A, Duba A, Shuman M, Logan JD (2013) Macroparasite population dynamics among geographical localities and host life cycle stages: eugregarines in Ischnura verticalis. J Parasitol 99:403-409. https://doi.org/10. 1645/ge-3137.1

Candolin U (2005) Why do multiple traits determine mating success? Differential use in female choice and male competition in a water boatman. Proc R Soc B Biol Sci 272:47-52. https://doi.org/10. 1098/rspb.2004.2932

Ceuppens B, Eeraerts M, Vleugels T, Cnops G, Roldan-Ruiz I, Smagghe $G$ (2015) Effects of dietary lambda-cyhalothrin exposure on bumblebee survival, reproduction, and foraging behaviour in laboratory and greenhouse. J Pest Sci 88:777-783. https://doi.org/10. 1007/s10340-015-0676-9

Charreton M, Decourtye A, Henry M, Rodet G, Sandoz JC, Charnet P, Collet C (2015) A locomotor deficit induced by sublethal doses of pyrethroid and neonicotinoid insecticides in the honeybee Apis mellifera. PLoS ONE 10:14. https://doi.org/10.1371/journal.pone. 0144879

Cole LC (1954) The population consequences of life history phenomena. Q Rev Biol 29:103-137. https://doi.org/10.1086/400074

Coors A, De Meester L (2008) Synergistic, antagonistic and additive effects of multiple stressors: predation threat, parasitism and pesticide exposure in Daphnia magna. J Appl Ecol 45:1820-1828. https://doi.org/10.1111/j.1365-2664.2008.01566.x

Córdoba-Aguilar A, Munguía-Steyer R (2013) The sicker sex: understanding male biases in parasitic infection, resource allocation and fitness. PLoS ONE 8:15. https://doi.org/10.1371/journal.pone. 0076246

Córdoba-Aguilar A, Salamanca-Ocaña JC, Lopezaraiza M (2003) Female reproductive decisions and parasite burden in a calopterygid damselfly (Insecta: Odonata). Anim Behav 66:81-87. https://doi.org/10.1006/anbe.2003.2198

Critchlow JT, Norris A, Tate AT (2019) The legacy of larval infection on immunological dynamics over metamorphosis. Philos Trans R Soc B Biol Sci 374:12. https://doi.org/10.1098/rstb.2019.0066

Dawkar VV, Chikate YR, Lomate PR, Dholakia BB, Gupta VS, Giri AP (2013) Molecular insights into resistance mechanisms of lepidopteran insect pests against toxicants. J Proteome Res 12:47274737. https://doi.org/10.1021/pr400642p

Desneux N, Pham-Delègue MH, Kaiser L (2004) Effects of sublethal and lethal doses of lambda-cyhalothrin on oviposition experience and host-searching behaviour of a parasitic wasp, Aphidius ervi. Pest Manag Sci 60:381-389. https://doi.org/10. $1002 /$ ps.822

Desneux N, Decourtye A, Delpuech JM (2007) The sublethal effects of pesticides on beneficial arthropods. Annu Rev Entomol 52:81106. https://doi.org/10.1146/annurev.ento.52.110405.091440

Dhakal S, Meyling NV, Pedersen KE, Cedergreen N, Fredensborg BL (2020) Timing of sub-lethal insecticide exposure determines parasite establishment success in an insect-helminth model. Parasitology 147:120-125. https://doi.org/10.1017/s0031182019001331

Dinh KV, Janssens L, Therry L, Gyulavári HA, Bervoets L, Stoks R (2016) Rapid evolution of increased vulnerability to an insecticide at the expansion front in a poleward-moving damselfly. Evol Appl 9:450-461. https://doi.org/10.1111/eva.12347

Dmitriew C, Rowe L (2011) The effects of larval nutrition on reproductive performance in a food-limited adult environment. PLOS ONE 6:6. https://doi.org/10.1371/journal.pone.0017399

Fauser-Misslin A, Sadd B, Neumann P, Sandrock C (2014) Influence of combined pesticide and parasite exposure on bumblebee colony traits in the laboratory. J Appl Ecol 51:450-459. https://doi.org/ $10.1111 / 1365-2664.12188$

Field SG, Michiels NK (2005) Parasitism and growth in the earthworm Lumbricus terrestris: fitness costs of the gregarine parasite Monocystis sp. Parasitology 130:397-403. https://doi.org/10. 1017/s0031182004006663

de França SM, Breda MO, Barbosa DR, Araujo AM, Guedes CA (2017) The sublethal effects of insecticides in insects. Biological control of pest and vector insects. Shields VDC, London, pp 23-39. https://doi.org/10.5772/66461

Gigliolli AAS, Lapenta AS, Ruvolo-Takasusuki MCC, Abrahão J, Conte H (2015) Morpho-functional characterization and esterase patterns of the midgut of Tribolium castaneum Herbst, 1797 (Coleoptera: Tenebrionidae) parasitized by Gregarina cuneata (Apicomplexa: Eugregarinidae). Micron 76:68-78. https://doi. org/10.1016/j.micron.2015.04.008

Gigliolli AAS, Julio AHF, Conte H (2016) The life cycle of Gregarina cuneata in the midgut of Tribolium castaneum and the effects of parasitism on the development of insects. Bull Entomol Res 106:258-267. https://doi.org/10.1017/s0007485315001121

Guedes NMP, Tolledo J, Corrêa AS, Guedes RNC (2010) Insecticideinduced hormesis in an insecticide-resistant strain of the maize weevil, Sitophilus zeamais. J Appl Entomol 134:142-148. https:// doi.org/10.1111/j.1439-0418.2009.01462.x

Guedes RNC, Smagghe G, Stark JD, Desneux N (2016) Pesticideinduced stress in arthropod pests for optimized integrated pest management programs. Annu Rev Entomol 61:43-62. https://doi. org/10.1146/annurev-ento-010715-023646

Guedes RNC, Walse SS, Throne JE (2017) Sublethal exposure, insecticide resistance, and community stress. Curr Opin Insect Sci 21:47-53. https://doi.org/10.1016/j.cois.2017.04.010 
Hafeez M, Qasim M, Ali S, Yousaf HK, Waqas M, Ali E, Ahmad MA, Jan S, Bashir MA, Noman A, Wang M, Gharmh HA, Khan KA (2020) Expression and functional analysis of P450 gene induced tolerance/resistance to lambda-cyhalothrin in quercetin fed larvae of beet armyworm Spodoptera exigua (Hübner). Saudi J Biol Sci 27:77-87. https://doi.org/10.1016/j.sjbs.2019.05.005

Häggström H, Larsson S (1995) Slow larval growth on a suboptimal willow results in high predation mortality in the leaf beetle Galerucella lineola. Oecologia 104:308-315. https://doi.org/10. 1007/bf00328366

Harry GO (1967) The effect of a eugregarine Gregarina polymorpha (Hammerschmidt) on the mealworm larva of Tenebrio molitor (L.). J Protozool 14:539-547. https://doi.org/10.1111/j.15507408.1967.tb02039.x

Hecker KR, Forbes MR, Léonard NJ (2002) Parasitism of damselflies (Enallagma boreale) by gregarines: sex biases and relations to adult survivorship. Can J Zool 80:162-168. https://doi.org/10. 1139/z01-213

Ilvonen JJ, Kaunisto KM, Suhonen J (2016) Are sexes equally parasitized in damselflies and dragonflies? Oikos 125:315-325. https:// doi.org/10.1111/oik.02437

Johny S, Muralirangan M, Sanjayan K (2000) Parasitization potential of two cephaline gregarines, Leidyana subramanii Pushkala and Muralirangan and Retractocephalus dhawanii sp. N. on the tobacco grasshopper, Atractomorpha crenulata (Fab.). J Orthoptera Res 9:67-70. https://doi.org/10.2307/3503635

Kim JI, Min JS, Kwon M, Choi JY, Lee SH (2014) Morphological and molecular characterizations of the Gregarina sp (Apicomplexa: Protozoa) parasitizing on Phaedon brassicae (Coleoptera: Chrysomelidae). J Asia Pac Entomol 17:1-5. https://doi.org/10. 1016/j.aspen.2013.08.008

Koch LK, Meunier J (2014) Mother and offspring fitness in an insect with maternal care: phenotypic trade-offs between egg number, egg mass and egg care. BMC Evol Biol 14:9. https://doi.org/10. 1186/1471-2148-14-125

Köhler HR, Triebskorn R (2013) Wildlife ecotoxicology of pesticides: can we track effects to the population level and beyond? Science 341:759-765. https://doi.org/10.1126/science.1237591

Locklin JL, Vodopich DS (2010) Patterns of gregarine parasitism in dragonflies: host, habitat, and seasonality. Parasitol Res 107:7587. https://doi.org/10.1007/s00436-010-1836-8

Logan JD, Janovy J, Bunker BE (2012) The life cycle and fitness domain of gregarine (Apicomplexa) parasites. Ecol Model 233:31-40. https://doi.org/10.1016/j.ecolmodel.2012.03.018

Margus A, Piiroinen S, Lehmann P, Tikka S, Karvanen J, Lindström L (2019) Sublethal pyrethroid insecticide exposure carries positive fitness effects over generations in a pest insect. Sci Rep 9:1-10. https://doi.org/10.1038/s41598-019-47473-1

Metcalfe NB, Monaghan P (2001) Compensation for a bad start: grow now, pay later? Trends Ecol Evol 16:254-260. https://doi.org/10. 1016/s0169-5347(01)02124-3

Moran NP, Caspers B, Chakarov N, Ernst U, Fricke C, Kurtz J, Lilie ND, Lo LK, Müller C, Takola E, Trimmer PC, van Benthem KJ, Winternitz J, Wittmann MJ (2020) Shifts between cooperation and antagonism driven by individual variation: a systematic synthesis review. EcoEvoRxiv. https://doi.org/10.32942/osf.io/sbrvu

Müller C (2018) Impacts of sublethal insecticide exposure on insectsfacts and knowledge gaps. Basic Appl Ecol 30:1-10. https://doi. org/10.1016/j.baae.2018.05.001

Müller T, Müller C (2016) Adult beetles compensate for poor larval food conditions. J Insect Physiol 88:24-32. https://doi.org/10. 1016/j.jinsphys.2016.02.009

Müller C, Rosenberger C (2006) Different oviposition behaviour in Chrysomelid beetles: characterisation of the interface between oviposition secretion and the plant surface. Arthropod Struct Dev 35:197-205. https://doi.org/10.1016/j.asd.2006.06.001
Müller C, Vogel H, Heckel DG (2017a) Transcriptional responses to short-term and long-term host plant experience and parasite load in an oligophagous beetle. Mol Ecol 26:6370-6383. https://doi. org $/ 10.1111 / \mathrm{mec} .14349$

Müller T, Prosche A, Müller C (2017b) Sublethal insecticide exposure affects reproduction, chemical phenotype as well as offspring development and antennae symmetry of a leaf beetle. Environ Pollut 230:709-717. https://doi.org/10.1016/j.envpol.2017.07.018

Müller T, Römer CI, Müller C (2019a) Parental sublethal insecticide exposure prolongs mating response and decreases reproductive output in offspring. J Appl Ecol 56:1528-1537. https://doi.org/ 10.1111/1365-2664.13398

Müller T, Gesing MA, Segeler M, Müller C (2019b) Sublethal insecticide exposure of an herbivore alters the response of its predator. Environ Pollut 247:39-45. https://doi.org/10.1016/j.envpol.2018. 12.040

Murphy AF, Krupke CH (2011) Mating success and spermatophore composition in western corn rootworm (Coleoptera: Chrysomelidae). Environ Entomol 40:1585-1594. https://doi.org/10.1603/ en11137

Pettis JS, vanEngelsdorp D, Johnson J, Dively G (2012) Pesticide exposure in honey bees results in increased levels of the gut pathogen Nosema. Naturwissenschaften 99:153-158. https://doi.org/10. 1007/s00114-011-0881-1

R Core Team (2020) R: a language and environment for statistical computing. R Foundation for statistical computing, Vienna, Austria. https://www.R-project.org/. Accessed 28 Oct 2020

Rivero A, Vézilier J, Weill M, Read AF, Gandon S (2010) Insecticide control of vector-borne diseases: when is insecticide resistance a problem? PLoS Pathog 6:9. https://doi.org/10.1371/journal.ppat. 1001000

RStudio Team (2019) RStudio: integrated development for R. RStudio, Inc., Boston, MA. http://www.rstudio.com/. Accessed 28 Oct 2020

Rueckert S, Betts EL, Tsaousis AD (2019) The symbiotic spectrum: where do the gregarines fit? Trends Parasitol 35:687-694. https:// doi.org/10.1016/j.pt.2019.06.013

Sanders RD, Poinar GO (1973) Fine structur and life cycle of Lankestria clarki sp. n. (Sporozoa: Eugregarinida) parasitic in mosquito Aedes sierrensis (Ludlow). J Protozool 20:594-602. https://doi. org/10.1111/j.1550-7408.1973.tb03582.x

Soderlund DM, Clark JM, Sheets LP, Mullin LS, Piccirillo VJ, Sargent D, Stevens JT, Weiner ML (2002) Mechanisms of pyrethroid neurotoxicity: implications for cumulative risk assessment. Toxicology 171:3-59. https://doi.org/10.1016/s0300-483x(01)00569-8

Soghigian J, Valsdottir LR, Livdahl TP (2017) A parasite's modification of host behavior reduces predation on its host. Ecol Evol 7:1453-1461. https://doi.org/10.1002/ece3.2748

Stark JD, Banks JE (2003) Population-level effects of pesticides and other toxicants on arthropods. Annu Rev Entomol 48:505-519. https://doi.org/10.1146/annurev.ento.48.091801.112621

Sulaiman I (1992) Infectivity and pathogenicity of Ascogregarina culicis (Eugregarinida: Lecudinidae) to Aedes aegypti (Diptera: Culicidae). J Med Entomol 29:1-4. https://doi.org/10.1093/jmede $\mathrm{nt} / 29.1 .1$

Syngenta (2016) Fact sheet LAMBDA WG. https://www.myagrar.de/ out/media/Gebrauchsanweisung_Lambda_2019-07-11_5166.pdf. Accessed 27 Feb 2020

Therneau $\mathrm{T}$ (2020) A package for survival analysis in $\mathrm{R}$. R package version 3.2-7. https://CRAN.R-project.org/package=survival. Accessed 28 Oct 2020

Thomas AM, Rudolf VHW (2010) Challenges of metamorphosis in invertebrate hosts: maintaining parasite resistance across life-history stages. Ecol Entomol 35:200-205. https://doi.org/10.1111/j. 1365-2311.2009.01169.x 
Tremmel M, Müller C (2013) The consequences of alternating diet on performance and food preferences of a specialist leaf beetle. J Insect Physiol 59:840-847. https://doi.org/10.1016/j.jinsphys. 2013.05.009

Venables WN, Ripley BD (2002) Modern applied statistics with S, 4th edn. Springer, New York

Wolz M, Schrader A, Müller C (2021) Direct and delayed effects of exposure to a sublethal concentration of the insecticide $\lambda$-cyhalothrin on food consumption and reproduction of a leaf beetle. Sci Total Environ. https://doi.org/10.1016/j.scitotenv.2020. 143381
Zuk M (1987a) The effects of gregarine parasites, body size, and time of day on spermatophore production and sexual selection in field crickets. Behav Ecol Sociobiol 21:65-72. https://doi.org/10.1007/ bf00324437

Zuk M (1987b) The effects of gregarine parasites on longevity, weight loss, fecundity and developmental time in the field crickets Gryllus veletis and G. pennsylvanicus. Ecol Entomol 12:349-354. https://doi.org/10.1111/j.1365-2311.1987.tb01014.x 